\title{
FORMAÇÃO DE PROFESSORES PARA DOCÊNCIA ONLINE: CONSIDERAÇÕES SOBRE UM ESTUDO DE CASO
}

\author{
Marco Silva* \\ Sheilane Avellar Cilento**
}

\section{RESUMO}

No Brasil, cresce exponencialmente a oferta de graduações na modalidade online, na medida em que a legislação oficial específica e as políticas públicas de inclusão social no ensino superior contam com as tecnologias digitais invadindo os mais distintos setores da vida social. No entanto, a expansão da modalidade online não tem sido acompanhada de formação docente adequada, particularmente entre os graduandos em pedagogia e aqueles professores que atuam em cursos na web. Este texto reúne algumas considerações sobre formação de professores para docência online extraídas de investigação acadêmica realizada com base no estudo de um caso brasileiro. $\mathrm{O}$ quadro teórico articula abordagens sobre: a) educação e cultura digital; b) docência no ensino superior; e c) formação para a docência online. As conclusões apontam para a necessidade de: a) desenvolver saberes docentes que contemplem a especificidades do meio online; b) desenvolver o diálogo entre professores e alunos enquanto parceiros que compartilham a construção do conhecimento e da comunicação; c) superar o uso das interfaces fórum e chat baseado na interação sem articulação, em favor da colaboração e interatividade; d) investir na formação continuada que proporcione ao docente aptidões pedagógicas específicas como expressão socioafetiva nas relações interpessoais com os cursistas e expertise tecnológica para promover a inclusão do cursista na dinâmica específica da aprendizagem online. Focado nesses desafios, o texto espera contribuir com o debate sobre a qualidade da formação de professores para docência online, quando a tendência ainda é a subutilização das potencialidades interativas da web e a reprodução de práticas unidirecionais da sala de aula presencial.

Palavras-chave: Docência online. Cultura digital. Formação de professores.

\section{ABSTRACT \\ TEACHER TRAINING FOR ONLINE TEACHING: CONSIDERATIONS ON A CASE STUDY \\ In Brazil, the offer of online graduation courses grows exponentially. This is due to the country's legislation, the public policies for social inclusion in higher education}

\footnotetext{
* Graduado em Ciências Sociais pela Universidade Federal do Rio de Janeiro (UFRJ). Mestre em Educação pela Fundação Getúlio Vargas (FGV-Rio). Doutor em Educação pela Universidade de São Paulo (USP). Professor da Faculdade de Educação da Universidade do Estado do Rio de Janeiro (UERJ). Endereço para contato: Av. Nossa Senhora de Copacabana, $\mathrm{n}^{\circ} 02$, ap. 101, Leme, Rio de Janeiro- RJ. CEP: 22010-121. mparangole@gmail.com

** Graduada em Português-Inglês e Literaturas pela Universidade Católica de Petrópolis (UCP). Mestre em Educação online pela Universidade Estácio de Sá (UNESA). Coordenadora do Curso de Pós- Graduação em Educação a Distância do Senac-RJ. smacrb@gmail.com
} 
and the invasion of digital technologies in the various aspects of our social lives. Nevertheless, the expansion of the online model has not yet been accompanied by the offering of adequate teacher training, particularly among Pedagogy undergraduates and online teachers. The present article presents some considerations on teacher training for online teaching, drawn from an academic research based on a Brazilian case study. The theoretical framework for this study includes: a) education and digital culture; $b$ ) higher education teaching and c) teacher training for online teaching. The research findings point to the need for: a) developing teacher knowledge which contemplates the specific pedagogical and technical characteristics of the online medium; b) developing a dialog between teachers and learners as partners who share knowledge building and communication; c) overcoming the use of forums and chat rooms as interfaces for interactions without exchange of knowledge between participants, in favour of peer collaboration and interactivity; d) investing in continuous professional development programmes, that enable the development of specific teaching skills, such as the acquisition of technological expertise and the development of socio-affective skills, in order to promote the inclusion of learners in the specific dynamics of online learning. Focusing on these challenges, this article aims at contributing to the discussion about the quality of teacher training for online teaching, in relation to the ongoing trend of underutilization of the interactive potential of the web and the repetition of traditional classroom teaching practices.

Keywords: Online teaching. Digital culture. Teacher training

\section{Introdução}

A modalidade educacional online que emerge com a web é recente, ganha centralidade no cenário da educação superior e, por isso mesmo, demanda pesquisas acadêmicas capazes de operar com o novo desafio que se apresenta à gestão dos sistemas de ensino e às teorizações pedagógicas consolidadas na sala de aula presencial. Na cultura digital ou cibercultura (LEMOS, 2007; LEMOS; LÉVY, 2010; LÉVY, 1997; SILVA, 2008), isto é, no cenário baseado na relação simbiótica entre sociedade, cultura e novas tecnologias de base microeletrônica conectadas à internet avançada, não basta o professor ter acesso e saber usar computador, tablet e celular conectados à internet, para lecionar na modalidade online. Ele precisa desenvolver saberes docentes específicos em diálogo permanente com os saberes construídos na modalidade presencial. É necessário mais investimento em pesquisas capazes de propiciar o fortalecimento e a oferta da formação para docência online. Os professores podem reinventar as práticas docentes classicamente construídas entre quatro paredes. Precisarão, para isso, construir uma nova identidade profissional capaz de atender às demandas sociais, culturais e profissionais em sintonia com o espírito do nosso tempo digital.

Para reinventar-se, é necessário que a educação possibilite dinâmicas pedagógicas capazes de superar a simples transmissão ou distribuição de informações. Para isso, o professor deveria estar inserido no contexto da cultura digital, desenvolvendo atitudes, modos de pensamento e práticas comunicacionais interativas no ciberespaço através de interfaces de autoria e de colaboração, como e-mails, wikis, redes sociais, blogs, chats.

O uso instrumental das tecnologias digitais e da web resulta na distribuição de informações e na administração burocrática do feedback dos cursistas. Para superar esse prejuízo à educação autêntica, o professor precisará operar com as tecnologias digitais de informação e comunicação em sintonia com uma estrutura curricular aberta, flexível e com um desenho didático interativo e hipertextual (SANTOS; SILVA, 2009).

Espera-se que, na cultura digital, o docente saiba operar com a informação em hipertexto e explorar as redes de comunicação em interatividade, isto é, como articulação da emissão e da recepção na cons- 
trução da mensagem e do conhecimento. Espera-se que saiba desenvolver uma pedagogia que contemple a dinâmica hipertextual e interativa da web. E que saiba lançar mão das potencialidades das interfaces online para proporcionar um aprendizado significativo aos sujeitos culturalmente imersos no novo cenário sociotécnico. Interfaces online são espaços de interlocução, de encontro das faces na $w e b$, potencialmente interativos, que permitem a mediação interpessoal, compartilhamento, socialização e construção colaborativa, ainda que na dispersão geográfica dos interlocutores. Essas disposições comunicacionais favoráveis à prática educacional dialógica e colaborativa demandam novos saberes docentes que podem ser desenvolvidos na formação continuada dos professores sintonizados com as mudanças sociotécnicas que emergem com a cultura digital (SILVA, 2005, 2014).

$\mathrm{O}$ docente precisa atentar para as especificidades da cultura digital no que tange às suas práticas comunicacionais, envolvendo e-mails, listas, blogs, jornalismo online, webcams, chats e novos empreendimentos que aglutinam grupos de interesse (cibercidades, games, software livre, ciberativismo, arte digital etc.). Com as possibilidades abertas pelo computador, verificamos novas possibilidades de tratamento da informação e da comunicação com infinitas articulações e caminhos a explorar, que vão exigir cada vez mais o uso dos sentidos (visão, audição, tato e voz), permitindo um maior envolvimento entre alunos e docentes. Temos, assim, a possibilidade de um processo educativo em que o aluno pode construir e expressar sua autoria de forma participativa, compartilhando com outros sujeitos, com base na troca interativa de saberes e na inteligência coletiva (SILVA, 2010; 2011).

O professor que não se mobilizou para operar em sala de aula com ajuda dos meios rádio e TV tem agora o desafio inarredável de se apropriar do laptop, do tablet e do celular conectados à web. Os primeiros, fundados na lógica da transmissão unidirecional massiva, são, portanto, de mais fácil apropriação docente, porque operam no mesmo paradigma comunicacional da sala de aula tradicional: a pedagogia da transmissão. Os meios digitais, mais complexos, fundados na autoria do usuário e na lógica da interatividade, demandam do professor nova postura comunicacional e superação da prevalência da prática docente unidirecional. Seu desafio aumenta na sala de aula online, onde os ambientes de gestão, docência e aprendizagem - plataforma de e-learning ou LMS (Learning Management System) - possuem características muito próprias e diferentes daquelas que conformam o ambiente físico da sala de aula presencial. A transição de um ambiente a outro não tem sido fácil para os docentes excluídos digitais e/ou habituados à pedagogia da transmissão. Isso revela a necessidade de formação específica que contemple o conhecimento da cultura digital ou cibercultura, bem como dos conteúdos, técnicas e metodologias a serem utilizadas em sintonia com o novo cenário sociotécnico (SILVA, 2012a; 2012b, 2012c).

A pesquisa que dá origem a este texto dedicou-se a estudar os desdobramentos de um curso online recente, destinado à formação de professores para docência no "campus virtual" de uma universidade privada de grande porte situada no Brasil. ${ }^{1}$ Tomou como objetivo geral investigar a atuação dos professores-cursistas nesse curso e verificar seu aproveitamento traduzido em práticas de docência online nos cursos de graduação dessa universidade. Seus objetivos específicos são: a) identificar as mudanças ocorridas na mediação da aprendizagem realizada por esses docentes a partir do curso; b) contrastar as concepções dos professores sobre a docência online antes e depois do curso; e c) apontar sugestões para a melhoria da docência online a partir das falas dos docentes, após a realização do curso.

A composição deste texto traz inicialmente aspectos gerais do contexto da pesquisa realizada e de seus procedimentos metodológicos. Em seguida, trata dos itens principais do seu quadro teórico, como cultura digital, saberes docentes, docência online no ensino superior e formação para docência online. Por fim, ao tratar das conclusões da pesquisa explicita os impasses e sucessos, bem como sugestões a favor da qualidade da formação de professores para a docência online.

\footnotetext{
1 Omitimos o nome da universidade que patrocinou o curso de formação docente investigado, visando garantir a privacidade dos seus professores-cursistas que, enquanto sujeitos da pesquisa, gentilmente atenderam às solicitações dos pesquisadores com transparência inquestionável.
} 


\section{Contexto da pesquisa e seus procedimentos metodológicos}

O curso "Formação para docência online" investigado contou com a participação de 334 docentes da universidade, distribuídos em dez turmas de 33 professores-cursistas cada. Teve a duração de 40 horas online distribuídas em três meses, incluindo mais 10 horas presenciais destinadas a dois encontros presenciais de cinco horas cada: um no início, para motivação e esclarecimentos sobre a formação, e outro no final, para avaliação da formação. Após seu término, 100 docentes seriam escolhidos por indicação de seus coordenadores e por seu desempenho no curso de formação para compor o grupo que ministra todas as disciplinas online da mesma instituição, atuando como autores dos conteúdos específicos de suas disciplinas específicas ("conteudistas") e como docentes dessas disciplinas. Eles trabalhariam reunidos em presença física na instituição, em regime de 10, 30 e 40 horas semanais, juntamente com toda a equipe responsável pela coordenação, gestão, implementação e "suporte de EAD". Essa característica particular favoreceu a investigação in loco sobre os objetivos pretendidos pela pesquisa no pós-curso, especificamente conviver com os docentes e, assim, criar um clima propício para descobrir as esperadas mudanças na mediação da aprendizagem que vinha correndo no "campus virtual" daquela universidade.

$\mathrm{O}$ processo investigativo iniciado com um mergulho no curso online destinado à formação de professores para a docência online, valendo-se da observação detalhada das atuações dos professores-cursistas nas diversas interfaces da plataforma de e-learning da universidade, aprofundou-se no pós-curso, tendo como base de observação o retrato vivo dos docentes em serviço, por meio de entrevistas individuais e em grupos focais. Trata-se, portanto, de uma pesquisa que buscou a compreensão do modus operandi da mediação docente promovido por uma formação específica, em uma instituição específica. Por essas características, entendeu-se que a pesquisa constitui um estudo de caso.

O estudo de caso é uma metodologia específica para orientar investigações de um caso individual, específico, bem delimitado, contextualizado em tempo e lugar, que contempla uma procura circunstanciada de informações. Os estudos de caso mais comuns visam à unidade, ou seja, têm caráter único, mas há também os que se caracterizam por serem múltiplos, nos quais vários estudos são realizados ao mesmo tempo, podendo se referir a indivíduos ou instituições. Para o âmbito desta investigação, voltada para um grupo de professores convidados à docência em uma instituição de ensino superior, a partir de seu engajamento bem avaliado em um curso específico promovido a convite da mesma instituição, e que passou a exercer de forma específica a docência online nessa instituição, admitiu-se a configuração do estudo de caso intrínseco ou particular (ANDRÉ, 1989; YIN, 2009).

Para a coleta de dados, foram utilizados questionários antes e depois do curso, de forma a identificar nas expressões dos professores-cursistas suas percepções a respeito da docência online e possíveis mudanças na mediação da aprendizagem construídas a partir do curso. Foram colhidas e mapeadas as falas desses professores, registradas em suas participações nas interfaces da plataforma de e-learning do curso, bem como em seus depoimentos e reflexões durante os encontros presenciais ocorridos no início e no final do curso. Durante o semestre letivo transcorrido imediatamente após o curso de formação, foram realizadas entrevistas individuais e grupos focais com os professores-cursistas engajados na docência de disciplinas das graduações no "campus virtual" da universidade. $\mathrm{Na}$ ocasião, ainda principiante na oferta de disciplinas online respaldada pela legislação brasileira (Portaria n. 4.059/2004) que permite, em graduações presenciais, a oferta de até $20 \%$ das disciplinas regulares na modalidade online, essa universidade exigia a presença física de cada docente no espaço físico do seu "campus virtual" para o cumprimento da sua carga horária na plataforma de $e$-learning. Justificava essa posição com o argumento da formação continuada "em serviço". Em suma, ter reunidos em um único espaço físico os professores que participaram do curso de formação favoreceu a realização das entrevistas individuais, os grupos focais e até mesmo o acompanhamento da performance de alguns docentes operando com seus alunos na tela dos seus computadores pessoais. Em observação 
participante, os pesquisadores puderam estar mais próximos da realidade institucional, captar os conflitos e tensões cotidianas, unindo o objeto a seu contexto, numa tentativa de identificar ali a sensibilidade e a motivação para as mudanças pretendidas (QUEIROZ et al., 2007).

\section{Docência no ensino superior}

A estrutura em que se organiza o ensino superior no Brasil, desde seu início, privilegia o domínio de conhecimentos e experiências profissionais, como requisitos suficientes para se lecionar em cursos universitários (MASETTO, 2008). Essa estrutura privilegia a transmissão de conhecimentos e experiências de um professor que sabe para um aluno que não sabe e não conhece. A crença é a de que quem detém o conhecimento sabe e, por conseguinte, pode ensinar. Contudo, há a crescente consciência de que o papel da docência no ensino superior precisa mudar, tendo em vista que, assim como em qualquer outra atividade profissional, os docentes necessitam de uma formação própria e específica, que "não se restringe a ter um diploma de bacharel, ou mesmo de mestre ou doutor, ou ainda, apenas o exercício de uma profissão" (MASETTO, 2003, p. 13). Falta-lhe a competência pedagógica para mediar a aprendizagem.

O modus operandi da docência no ensino superior segue basicamente o mesmo padrão consolidado na experiência discente de cada professor desde sua escola básica. Esse padrão, segundo Vilarinho (1984), pode ser assim identificado: a) o objetivo básico do ensino é o domínio do conteúdo de estudo; b) o ensino é sinônimo de transmissão de conhecimentos; c) o professor é o elemento mais importante do processo, pois representa a autoridade máxima, que detém o saber e o poder de avaliar o aluno; d) o aluno recebe, aceita e reproduz o conhecimento transmitido; e) o conteúdo de aprendizagem é um fim em si mesmo, sendo organizado segundo a lógica do professor para ser memorizada pelo aluno; f) o método da docência é a exposição oral, ou seja, tem cunho verbalista, transmissivo e se projeta para a dimensão intelectual do aprendiz; g) as orientações da aprendizagem são coletivas, desconsiderando-se as diferenças individuais.
O ensino superior, e certamente também o escolar, requer mudança na postura docente. O especialista que transmite seu conhecimento precisa formar-se para atuar como mediador que promove a construção da comunicação e do conhecimento, nas modalidades presencial e online. Ainda segundo Masetto (2003), o principal foco de mudança encontra-se na própria ação do professor, que deixa de ser o centro do processo e passa para um cenário de aprendizagem em que o aprendiz (aqui compreendendo tanto o professor como o aluno) ocupa a centralidade. É preciso que docente e aluno tornem-se parceiros e coparticipantes do mesmo processo.

Essa transformação supõe uma formação em que se repensem as competências básicas para realização da docência no ensino superior. Juntamente com a competência pedagógica e técnica, o professor poderá desenvolver: a) competências socioafetivas que permitam estabelecer relações interpessoais com os alunos e favorecer a criação de um ambiente propício à aprendizagem; b) competências para organizar seu tempo, para gerenciar as atividades e procedimentos do curso; e c) competências tecnológicas que orientem a inclusão do aluno na dinâmica específica da plataforma de e-learning. Igualmente relevante é a atenção dada ao aluno, de forma individual, em pequenos grupos ou no grupo como um todo. $\mathrm{O}$ termo "competência", aqui utilizado, diz respeito à "aptidão para enfrentar um conjunto de situações análogas, mobilizando, de uma forma correta, rápida, pertinente e criativa, múltiplos recursos cognitivos: saberes, capacidades, informações, valores, atitudes, esquemas de percepção, de avaliação e de raciocínio" (MASETTO, 2003, p. 25).

O docente precisará ainda preparar-se para lidar com os aprendizes que operam facilmente com a hipermídia e que, quando lidam com texto, fazem-no mais facilmente através de links, de palavras-chave, como hipertexto. Portanto, precisará situar-se mais próximo da sensibilidade deles, das suas formas mais imediatas de compreensão. Ao mesmo tempo, poderá levar em consideração o mundo e a cultura dos aprendizes, para que possa atender aos seus anseios, curiosidades e questionamentos, diminuindo a distância entre o mundo do professor (aqui compreendidas também as instituições) e o mundo do aluno. 
A sociedade imersa no cenário midiático dinâmico, aberto, em rede e interativo requer processos pedagógicos também dinâmicos, abertos, rizomáticos e interativos. Para contemplar essa demanda sociotécnica, a mediação docente precisará operar fluentemente com a autoria, compartilhamento, conectividade e colaboração, possibilitando ao aprendiz relacionar-se e posicionar-se nessa ambiência cibercultural. $\mathrm{O}$ docente poderá equipar a sala de aula com agenciamentos de comunicação capazes de contemplar o perfil comunicacional do novo espectador, permitindo que os alunos desenvolvam com ele interatividade efetiva, entendida, por sua vez, como articulação viva da emissão-mensagem-recepção que promove a construção colaborativa do conhecimento $\mathrm{e}$ da própria comunicação.

O cenário midiático na era digital amplia os mercados culturais e é responsável pela expansão e criação de novos hábitos de consumo, tendo no computador, tablet e celular os veículos que possibilitam converter a mensagem em texto, som, imagem, vídeo numa linguagem acessível a todos. A digitalização, a compressão e a convergência das mídias digitais favorecem a manipulação, armazenamento, reprodução, modificação e distribuição fácil dos dados. Há, portanto, uma mudança na relação receptiva de sentido único com o televisor, para o modo interativo e multidirecional nas telas digitais conectadas à web (SANTAELLA, 2008).

Imersos e desenvoltos nesse cenário, os aprendizes são capazes de, ao mesmo tempo, assistir a um vídeo, enviar uma mensagem de texto para diferentes destinatários e conversar em tempo real. Eles gostam de experimentar novos games, participar de redes sociais online, visitar blogs e sites, compartilhar dados e conversar via MSM, Hangout, WhatsApp, Skype etc. Essa expertise favorece sua atuação na plataforma de e-learning, ainda que aqui o nível de engajamento exigido seja diferenciado, o que vai demandar do professor sensibilidade, proximidade e desenvoltura digital semelhante associadas aos saberes docentes específicos. No entanto, os professores ainda estão se integrando à mídia digital e muitos ainda o fazem com restrições. Nesse contexto, entender a transição da cultura audiovisual própria dos meios de massa para a interatividade encontrada na cultura digital é fator decisivo para se operar com o perfil comunicacional e cognitivo do aprendiz, bem como para se reinventar a formação continuada da docência online no ensino superior.

\section{A formação para a docência online}

O professor na modalidade online traz, naturalmente, consigo os saberes docentes adquiridos ao longo de sua prática presencial. Tardif (2007), um renomado pesquisador dos "saberes docentes", não aborda a extensão do modus operandi presencial na modalidade online, mas sugere que, quando não teve formação específica para operar na modalidade online, o docente certamente trará consigo a sua experiência construída. Para esse autor, os saberes docentes construídos ao longo da carreira profissional levam o professor a aprender, progressivamente, a dominar o ambiente em que trabalha. $\mathrm{O}$ saber docente consolida-se essencialmente na prática pessoal da sala de aula, estando ligado à pessoa, sua identidade, experiência de vida e trajetória profissional. A pesquisa observou que o curso de formação investigado atentou para essa abordagem e a tomou como quadro teórico, com a finalidade de incentivar o diálogo entre os saberes docentes consolidados na modalidade presencial e aqueles demandados pela modalidade online.

Existenciais, sociais e pragmáticos, os saberes docentes trazidos da história de vida do professor em sala de aula presencial podem ser transpostos para a sala de aula online. Contra a tendência da mera transposição que se acomoda à nova modalidade, será necessária a atitude de investigação, a ser mantida pelo professor, sobre o seu ambiente sociotécnico e sobre sua atuação na plataforma de e-learning. Para não subutilizar as potencialidades comunicacionais desta, para não subestimar o perfil comunicacional dos cursistas, para não comprometer a formação e a educação, será preciso promover o diálogo constante dos saberes em jogo.

Através das mediações nas interfaces de comunicação e colaboração utilizadas, o curso "Formação para docência online" insistiu com os professores cursistas nos aspectos sintetizados no subtítulo anterior e no diálogo entre os saberes 
docentes. Os questionários aplicados, as entrevistas e grupos focais realizados revelaram que os professores-cursistas que concluíram satisfatoriamente o curso de formação se sentiram mais desafiados e motivados diante de três conteúdos de aprendizagem trabalhados: 1) ser docente na web é estar pessoal e coletivamente engajado na autoria de um novo estilo de mediação da aprendizagem; 2) comunicar não é simplesmente distribuir conteúdos de aprendizagem e cobrar o feedback solitário do aluno, mas oferecer múltiplas disposições à intervenção do interlocutor, que participa por meio de coautoria da mensagem e da aprendizagem; e 3) o conhecimento é construído por meio de interlocuções, transformações e enriquecimentos entre professores e alunos, uma vez que ambos ensinam e aprendem em colaboração, em coautoria.

O curso de formação enfatizou que não se trata de negar o ensino tradicional, mas de dialogar com ele e, assim, redimensionar a ação docente e discente nas modalidades presencial e online. Os professores-cursistas puderam experimentar aspectos essenciais da formação operando com o desenho didático do curso - arquitetura hipertextual que articula conteúdos, atividades e avaliações - e com a mediação docente. As exigências de qualidade mais enfatizadas no curso foram:

- Hipertexto: é preciso contemplar o hipertexto que, em sua forma não sequencial, permite: 1) articular nas interfaces conteúdos e atividades de aprendizagem em hipermídia, isto é, em convergência de vários suportes midiáticos abertos a novos links e agregações e de várias linguagens - som, texto, imagens, vídeo, mapas; 2) transformar a leitura em escritura através de conexões autorais em rede.

- Mediação docente interativa: é preciso internalizar que mediar a aprendizagem não é meramente distribuir conteúdos e atividades de aprendizagem, tirar dúvidas e cobrar o feedback dos cursistas; é potencializar suas autorias colaborativas nas interfaces, seja formulando problemas, provocando interrogações, coordenando grupos de trabalho, sistematizando experiências e conhecimentos construídos com base no diálogo entre interlocutores.
- Avaliação formativa e contínua: é preciso superar o modelo de avaliação da aprendizagem baseada no exame pontual solitário, em favor da avaliação formativa e contínua, que opera nas interfaces de comunicação e colaboração com base em critérios, indicadores e instrumentos previamente negociados coletivamente como competentes para resultar em salto qualitativo na comunicação todos-todos, na aprendizagem e na formação.

A análise da atuação dos professores-cursistas que concluíram satisfatoriamente o curso "Formação para docência online" permitiu constatar que eles tiveram oportunidade de vivenciar desafios da docência e da aprendizagem na cultura digital, diante do aluno a exigir deles um novo modus operandi. Foram alertados insistentemente para o risco de serem atropelados pela força do hábito sedimentado no saber docente que faz reproduzir nas aulas online os mesmos métodos já questionados em suas aulas presenciais, resultando na sua insatisfação existencial e profissional, bem como em grave prejuízo na formação e educação dos cursistas. E compreenderam que o docente pode mobilizar os seus alunos para a conquista do direito de se situarem na cultura digital, de dialogar com ela e de criticar seus usos e abusos em consumos banais e inconsequentes, construindo, a partir da interlocução competente na plataforma de e-learning, a cibercidadania que diz respeito à construção da democracia participativa no espaço e no ciberespaço.

Será preciso, portanto, que o sistema educacional em geral e cada instituição de ensino em particular se organizem estruturalmente para investir na formação continuada dos seus docentes, de maneira a mobilizá-los para a nova sala aula feita à base de fóruns, chats, wikis, blogs, webconferências etc., inserindo-os na cultura digital e na construção da expertise necessária à dinâmica interativa do ensino online. Em suma, é preciso ter bem claro que a formação contínua para docência online é essencial. Entretanto, a última palavra estará sempre com o professor atento, inquieto e mobilizado a realizar o diálogo dos saberes, em sintonia com o cenário sociotécnico passado, presente e futuro. 


\section{Conclusão}

Esta conclusão vem finalizar o tratamento dos dados da pesquisa que investigou o curso "Formação para docência online" e o pós-curso, isto é, a atuação docente dos professores-cursistas no "campus virtual" da sua universidade durante o semestre letivo imediatamente posterior a esse curso. Até aqui, o texto explorou os principais itens do quadro teórico adotado pelo curso: cultura digital, saberes docentes, docência no ensino superior e formação para docência online. Ao fazê-lo, assume sua relevância para o tratamento do tema investigado e cria expectativas sobre seu impacto na atuação dos professores-cursistas no curso, bem como sobre seu aproveitamento traduzido em novas práticas de docência online. A seguir, o tratamento do impacto e do aproveitamento diz respeito à prestação de contas aos objetivos da pesquisa apresentados na introdução.

Os depoimentos dos professores-cursistas no início do curso de formação revelam o perfil típico do docente despreparado para a modalidade online. Três de suas expressões revelam o mal-estar comum a muitos deles: "sinto falta da presença do aluno"; "somente o contato com suas fotografias no ambiente virtual não satisfaz"; " $n a ̃ o$ tenho segurança de que meus alunos estão aprendendo efetivamente os conteúdos, já que não posso olhar o olhar deles e vigiar de perto suas avaliações".

Essa inquietação revela, de antemão, que esses professores subutilizavam as interfaces de interlocução e colaboração da plataforma de $e$ -learning. Revela que eles não sabiam construir o olho-no-olho nos fóruns ou chats. Certamente que a intensidade do presencial é insubstituível, entretanto é preciso considerar que muitas vezes, no presencial, nosso olhar pode ser extremamente superficial e distante, como um olhar que não vê. Ao passo que em uma clássica correspondência via cartas em papel pode-se viver a experiência de uma profunda proximidade. A inquietação em busca do controle dos alunos através do olhar e do vigiar físicos é herdeira da sala de aula presencial e revela, por sua vez, o desafio da formação de professores que passa necessariamente pela construção da inclusão cibercultural capaz de permitir o estar-junto online, mais intenso que aquele mais comum nas redes sociais da web. $\mathrm{O}$ professor que leciona online precisará criar uma atmosfera amigável e de proximidade entre os cursistas, que possibilite a convivência de interlocutores em comunidade de comunicação e aprendizagem. Precisará motivá-los a estabelecer parcerias e colaboração, essenciais para a construção coletiva do conhecimento. De resto, o mesmo vale para a sala de aula presencial, quando se pretende educação autêntica.

O questionário aplicado no início do curso revela ainda que os docentes, responsáveis por disciplinas online na universidade há um ou dois anos, encontravam-se em diversas dificuldades. A mediação interpessoal, a troca e o compartilhamento entre cursistas era incipiente. Suas disciplinas eram oferecidas com conteúdos e atividades de aprendizagem para o trabalho solitário dos cursistas, na lógica da atuação tarefeira e na ausência da mediação docente.

$\mathrm{O}$ e-mail cadastrado na plataforma é a interface mais utilizada pelo professor (36\%) para encaminhar e cobrar atividades, tirar dúvidas, lembrar tarefas pendentes e agenda da disciplina. $O$ fórum é a segunda interface mais usada pelos docentes $(35 \%)$. Em sua maioria, na lógica da interação sem articulação, isto é, há um enunciado e diversas mensagens individuais referentes a ele. Não é costumeiro cursista conversar com cursista. Interlocução, colaboração, construção coletiva do conhecimento é raridade. E o que é mais grave: as mensagens se avolumam em resposta a um enunciado, e o professor nem sempre aparece para se posicionar a respeito. $O$ efeito disso é a diminuição das participações dos cursistas nos fóruns e a subutilização de uma potente interface para o exercício da mediação docente. Quanto ao chat, $40 \%$ dos docentes não utilizam essa interface de comunicação síncrona, na qual poderiam estar em tempo real com toda a turma ou com grupos isolados. E há ainda o "diário de bordo", ferramenta com que cada aluno registra sua itinerância, suas reflexões pessoais, podendo tornar-se interface, quando aberta aos outros cursistas para leitura, interlocução e cocriação dos seus conteúdos. Apenas $29 \%$ dos professores lançaram mão desse quarto recurso.

A justificativa mais citada pelos professores-cursistas para a baixa apropriação e utilização dos recursos de interatividade disponíveis na plataforma de e-learning é a ocupação excessiva 
à frente de turmas numerosas. De fato, muitas turmas numerosas resultam em um grande volume de postagens nas interfaces, o que inviabiliza a mediação docente. Os professores com dez horas/ aula semanais eram responsáveis por cinco turmas que totalizavam 300 alunos. Com 30 horas/aula, 15 turmas e até 900 alunos. E os professores com 40 horas semanais eram responsáveis por 20 turmas e 1.200 alunos. Um absurdo! Entretanto, o maior disparate apareceu na justificativa da direção do "campus virtual" para o exagerado número de cursistas por docente: "poucos alunos participam". A própria instituição universitária legitima a não participação dos cursistas, dos professores e ainda tira proveito financeiro disso!

Problemas de usabilidade e funcionalidade na plataforma de e-learning são a segunda justificativa mais citada pelos professores-cursistas para a baixa utilização dos recursos de interatividade. Associado a isso, alegaram a centralização da gestão da infraestrutura da sala de aula online nas mãos da equipe técnica do "campus virtual". Abertura e fechamento de fóruns, chats ou ajustes nos conteúdos de aprendizagem era responsabilidade da equipe técnica, que, assoberbada com muitas demandas dos professores, atrasava na apresentação de soluções, gerando um acúmulo de prejuízos para a mediação docente e para a aprendizagem.
Enfrentar e superar as fragilidades da mediação docente tornou-se, portanto, foco principal do curso "Formação para docência online". Os professores-cursistas foram estimulados a trazer para o debate suas dificuldades explicitadas ou não no questionário inicial. A respeito do número excessivo de alunos por professor, a formação deu o exemplo: dividiu os 334 professores-cursistas em dez turmas com pouco mais de 30 docentes cada e lançou mão da mesma plataforma de e-learning, tendo em vista, inclusive, a formação para seu uso adequado. Ao mesmo tempo, deixou claro que não ter autonomia para gerir o desenho didático de suas disciplinas é fragilizar a mediação docente.

Para além do tratamento específico de fragilidades da mediação docente, o tema de base mais trabalhado, a partir da confluência dos itens do quadro teórico da pesquisa, foi a mediação docente baseada na prática da colaboração e interatividade, como superação da interação sem articulação (Figura 1). Dez professores-mediadores foram convidados para atuar na formação, todos hábeis e sabendo como promover a superação da interação sem articulação. Cada um, dedicado a uma única turma com pouco mais de 30 professores-cursistas, mostrou na prática como desenvolver colaboração e interatividade nas interfaces fórum e chat.

Figura 1 - Modelos de interação no fórum e no chat

Interação sem articulação

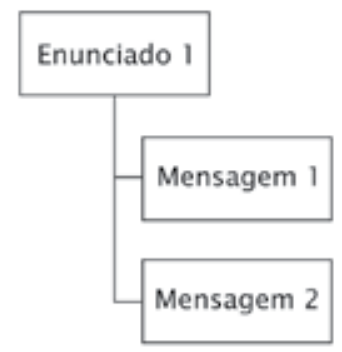

Colaboração, interatividade

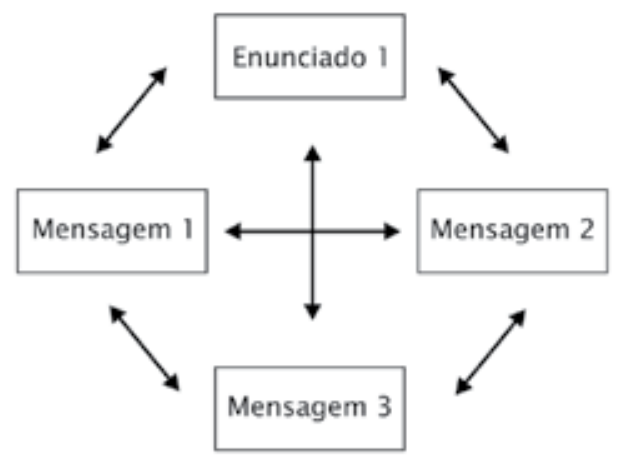

Fonte: Elaborada pelos autores. 
Os professores-docentes do curso de formação puseram em prática um conjunto de ações visando à criação de uma ambiência comunicacional muito precisa. Todas previamente acordadas em reuniões com a coordenação da formação. São elas:

- provocar situações de inquietação criadora;

- promover ocasiões que despertem a coragem do enfrentamento online diante de situações que provoquem reações individuais e grupais;

- encorajar esforços no sentido da troca entre todos os envolvidos, juntamente com a definição conjunta de atitudes de respeito à diversidade e à solidariedade;

- incentivar a participação dos cursistas na resolução de problemas apresentados, de forma autônoma e cooperativa;

- elaborar problemas que convoquem os cursistas a apresentar, defender e, se necessário, reformular seus pontos de vista constantemente;

- formular problemas voltados para o desenvolvimento de competências que possibilitem ao aprendiz ressignificar ideias, conceitos e procedimentos;

- implementar situações de aprendizagem que considerem as experiências, os conhecimentos e as expectativas que os estudantes já trazem consigo;

- desenvolver atividades que não só propiciem a livre expressão, o confronto de ideias e a colaboração entre os estudantes, mas que permitam, também, o aguçamento da observação e da interpretação das atitudes dos atores envolvidos;

- responder às postagens dos cursistas em até 24 horas, não mais.

A pesquisa verificou que essas ações promoveram a construção do aprendizado sobre como superar o modus operandi com o qual os professores-cursistas estavam habituados. Na fase pós-curso, o questionário, as entrevistas individuais e os grupos focais revelaram que os professores-cursistas que concluíram satisfatoriamente a formação tornaram-se críticos da interação sem articulação e se entusiasmaram com o salto de qualidade possível baseado na colaboração e na interatividade (Quadro 1).

Quadro 1 - Modelos de mediação docente

\begin{tabular}{|l|l|l|}
\hline & \multicolumn{1}{|c|}{ Interação sem articulação } & Colaboração e interatividade \\
\hline $\begin{array}{l}\text { Mediação } \\
\text { docente nas } \\
\text { interfaces da } \\
\text { plataforma de } \\
\text { e-learning }\end{array}$ & $\begin{array}{l}\text { Anstrucionista, transmissiva e tarefista. } \\
\text { solitária do cursista e nas relações } \\
\text { assimétricas, verticais: autor/emissor } \\
\text { separado de aprendiz/receptor. } \\
\text { Cursista pouco interage com cursista. } \\
\text { Vinculação um-todos separados pela } \\
\text { distância físico-geográfica }\end{array}$ & $\begin{array}{l}\text { Construcionista, interacionista e } \\
\text { colaborativa. Relações horizontais } \\
\text { abertas à colaboração e à coautoria. O } \\
\text { docente é um proponente da formação. } \\
\text { Juntamente com os cursistas promove } \\
\text { a cocriação da comunicação e do } \\
\text { conhecimento. Vinculação todos-todos } \\
\text { em presença "virtual" nas interfaces. }\end{array}$ \\
\hline
\end{tabular}

Fonte: Elaborado pelos autores deste artigo.

Nem todos os professores-cursistas concluíram a formação satisfatoriamente. Os critérios de avaliação do aproveitamento no curso de formação foram definidos em comum acordo com os professores-docentes e os professores-cursistas, com base na participação quantitativa e qualitativa nas interfaces fórum, chat, diário de bordo e e-mail. A participação de maior qualidade foi assim con- siderada tendo em vista a maior correspondência com a mediação docente baseada na colaboração e interatividade. Definiu-se como maior aproveitamento aquele garantido mediante participação acima de 70\%; aproveitamento mediano, de 50 a 70\%; e menor aproveitamento, de 20 a 49\%. Assim, somente $25 \%$ dos professores-cursistas tiveram avaliação máxima, 14\% tiveram avaliação mediana 
e $42 \%$ tiveram menor aproveitamento. Dos 334 professores inscritos, $19 \%$ não acessaram uma vez sequer o curso de formação.

As justificativas para as participações mediana e menor, que somadas são $56 \%$, variam em torno de queixas que podem ser resumidas na fala de um dos professores-cursistas: "nas conversas de corredores, tenho constatado que nós, agora alunos, não estamos conseguindo acompanhar as atividades propostas, pois, como professores, temos muitas obrigações urgentes a serem cumpridas também. Escuto muitos, como eu, a lamentar por não poderem fazer o curso com mais calma, com leituras mais atentas, maiores participações nos fóruns e nos chats, por não conseguirem cumprir os prazos de postagem em fóruns, por exemplo". Os professores-docentes manifestaram respeito a esse tipo de justificativa, tendo em vista que, durante a formação, permaneceu o regime de 10,30 e 40 horas/aula, com turmas que totalizam respectivamente 300,900 e 1200 alunos. Diante desse quadro esdrúxulo, praticamente todos revelaram admiração pela força de vontade dos $25 \%$ que tiveram maior aproveitamento. Ainda assim se engajaram no que ficou conhecido como "operações-resgate", lançando mão de expedientes como "chats queijos e vinhos" para encontros online festivos, vídeos de motivação e e-mails personalizados.

Nas avaliações negativas feitas pelos professores-cursistas à formação, apareceram outras explicações para a média e baixa participação. Para alguns, houve um excesso de leituras propostas nas primeiras aulas que, somadas aos afazeres docentes no "campus virtual", prejudicaram o aproveitamento. Outros criticaram a instabilidade da plataforma de e-learning, alegando que não conseguiram acessar, navegar, operar com suas interfaces em finais de semana, quando a plataforma esteve "fora do ar" para manutenção. Por último, aqueles que criticaram sua baixa funcionalidade ou usabilidade e não puderam contar com o helpdesck para tratar de questões de ordem prática e técnicas referentes ao uso de chats, fóruns e diário de bordo. Essa queixa surpreendeu os professores-docentes, uma vez que os cursistas eram docentes online na instituição há pelo menos dois semestres e, além disso, tiveram o passo-a-passo para o uso das interfaces da plataforma de e-learning oferecido no início da formação.
Quanto aos docentes que não acessaram o curso, eles somaram 19\% ou 63 inscritos. À primeira vista esse parece um número bastante elevado, tendo em vista que a instituição ofereceu o curso gratuitamente e online, com apenas dois encontros presenciais. Entretanto, entre esses docentes, verificou-se que alguns foram inscritos como observadores da instituição, outros como membros da equipe técnica do "campus virtual" que acompanharam de perto a funcionalidade da plataforma de e-learning e, ainda, aqueles inscritos muito depois do início do curso e que não se encorajaram a "pegar o bonde andando".

$\mathrm{O}$ aproveitamento traduzido em novas práticas no "campus virtual" ou em sugestões de melhoria para a docência online apareceu nos depoimentos dos professores-cursistas que concluíram satisfatoriamente o curso de formação. No pós-curso, através do questionário, das entrevistas e dos grupos focais, acusaram entusiasmados uma melhoria substancial em sua desenvoltura para a construção colaborativa da comunicação todos-todos e da aprendizagem nas interfaces da plataforma de e-learning. Ressaltaram as trocas realizadas, os relatos de experiências e as discussões ocorridas nos diversos fóruns temáticos, demonstrando que a interatividade é possível quando ocorre horizontalidade, proximidade e cocriação. Os fóruns, inspirados no modus operandi da colaboração e interatividade, motivaram os cursistas à mediação docente capaz de superar a reatividade burocrática e solitária diante de um enunciado. Os chats, por sua vez, reunindo pequenos grupos em horários alternativos, possibilitaram vivenciar a multidirecionalidade todos-todos em tempo real para tomada de decisões ou esclarecimentos e foram percebidos como espaços privilegiados para construção do sentimento de pertencimento e de vínculos de afetividade.

A formação para professorar online materializou em sua prática engajamentos específicos da mediação docente nos fóruns e chats. Ofereceu diretrizes claras para a atuação dos cursistas, incentivou e acompanhou os trabalhos em grupos, estimulou e orientou a cooperação na apresentação de projetos, nas tarefas desafiadoras, nos estudos de caso, respeitou os diferentes talentos e estilos de aprendizagem, valorizou as participações, resgatou postagens dos cursistas e tornou-as proposições de 
aprendizagem, incentivou a contribuição discente na melhoria do desenho didático, valorizou a expressão de diferentes pontos de vista sobre temas polêmicos e mostrou a importância de se tentar consensos provisórios. Por fim e por princípio, mobilizou a participação ativa e coautoral dos cursistas para a construção dos critérios de funcionamento do curso, da avaliação da aprendizagem e da própria formação para docência online.

Em suma, as conclusões confirmam prioridades e encaminhamentos para a construção da qualidade na modalidade educacional online, particularmente no campo específico da mediação docente da comunicação e da aprendizagem.

\section{REFERÊNCIAS}

ANDRÉ, M. E. D. Estudo de caso: seu potencial na educação. Cadernos de Pesquisa, v. 49, p. 51-54, maio 1989. LEMOS, A. Cibercultura: tecnologia e vida social na cultura contemporânea. 3. ed. Porto Alegre: Sulina, 2007. LEMOS, A.; LÉVY, P. O futuro da internet: em direção a uma ciberdemocracia planetária. São Paulo: Paulus, 2010. LÉVY, P. Cibercultura. Lisboa: Instituto Piaget, 1997.

MASETTO, M. T. Competência pedagógica do professor universitário. São Paulo: Summus, 2003. Docência na universidade. Campinas, SP: Papirus, 2008.

QUEIROZ, D. T.; VALL, J.; SOUZA, A, M, A; VIEIRA, N. F. C. Observação participante na pesquisa qualitativa: conceitos e aplicações na área da saúde. Revista Enfermagem UERJ, Rio de Janeiro, v. 15, n. 2, p. 273-283, abr./ jun. 2007.

SANTAELLA, L. Culturas e artes do pós-humano: da cultura das mídias à cibercultura. 3. ed. São Paulo: Paulus, 2008.

SANTOS, E.; SILVA, M. Desenho didático interativo para educação online. Revista Iberoamericana de Educación, n. 49, enero-abril, 2009. Disponível em: <http://www.rieoei.org/rie49a11.htm>. Acesso em: 14 maio 2014.

SILVA, M. Educación interactiva: enseñanza y aprendizaje presencial y online. Barcelona: Gedisa, 2005.

Cibercultura e educação: a comunicação na sala de aula presencial e online. Revista Famecos, Porto Alegre, n. 37, p. 69-74, dez. 2008.

. Desenho didático: contribuições para a pesquisa sobre formação de professores para docência online. In: SILVA, M.; PESCE, L.; ZUIN, A. (Org.). Educação online: cenário, formação e questões didático-metodológicas. Rio de Janeiro: WAK, 2010. p. 215-232.

. O fundamento comunicacional da avaliação da aprendizagem na sala de aula online. In: SANTOS, E.;

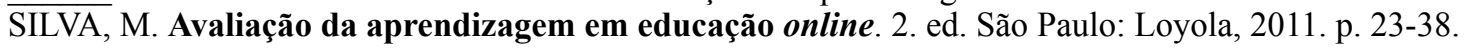

. Sala de aula interativa. 7. ed. São Paulo: Loyola, 2014.

. Formação de professores para docência online: uma experiência de pesquisa online com programas de pós-graduação. In: SILVA, M. (Org.) Formação de professores para docência online. São Paulo: Loyola, 2012a. p. 11-28.

Educação e comunicação interativas: contribuições para o desenho didático e para a mediação docente na educação online. In: SILVA, M. (Org.) Formação de professores para docência online. São Paulo: Loyola, 2012b. p. 87-109.

. Criar e professorar um curso online. In: SILVA, M. (Org.). Educação online: teorias, práticas, legislação e formação corporativa. 4. ed. São Paulo: Loyola, 2012c. p. 53-76.

TARDIF, M. Saberes docentes e formação profissional. 8. ed. Petrópolis, RJ: Vozes, 2007.

VILARINHO, L. R. G. Didática: temas selecionados. Rio de Janeiro: Livros Técnicos e Científicos, 1984.

YIN, R. K. Case study research: design and methods. 4. ed. London: Sage, 2009.

Recebido em: 13.06.2014

Aprovado em: 01.10.2014 